\title{
Nanoparticle formation of chitosan induced by 4-sulfonatocalixarenes: Utilization for alkaloid encapsulation
}

\author{
József G. Harangozó, ${ }^{a}$ Véronique Wintgens, ${ }^{b}$ Zsombor Miskolczy, ${ }^{a}$ Catherine Amiel, \\ László Biczók ${ }^{\mathrm{a}, *}$
}

${ }^{a}$ Institute of Materials and Environmental Chemistry, Research Centre for Natural Sciences, Hungarian Academy of Sciences, P.O. Box 286, 1519 Budapest, Hungary

${ }^{b}$ Systèmes Polymères Complexes, ICMPE, 2 rue Henri Dunant, 94320 Thiais, France

\begin{abstract}
Spontaneous formation of positively charged nanoparticles was observed upon mixing more than stoichiometric amount of chitosan with 4-sulfonatocalix[8]arene (SCX8) in acidic solution. The particle size did not change with SCX8 concentration, polymer chain length and the degree of deacetylation at $0.002 \leq \mathrm{SCX} 8$ :chitosan $\leq 0.043$ molar ratios in $0.01 \mathrm{M} \mathrm{HCl}$. However, larger aggregates were produced when chitosan concentration was increased. The most stable nanoparticles with $160 \mathrm{~nm}$ diameter and narrow size distribution were obtained at pH 4 using low molecular weight chitosan. These particles encapsulated coralyne with more than $90 \%$ entrapment efficiency and $15 \%$ loading capacity. A loading ratio of [coralyne]/[SCX8] = 1.7 was achieved without any stability loss. 4-Sulfonatocalix[4]arene induced the formation of slightly smaller nanoparticles than its homologues comprising 6 or 8 phenol units.
\end{abstract}

Key words: nanoparticles; self-assembly; host-guest complex; alkaloid; polyelectrolyte

\footnotetext{
* Corresponding author. Phone: (+36 1) 382-6614; E-mail: biczok.laszlo@ttk.mta.hu
} 


\section{Introduction}

Chitosan is a biocompatible and biodegradable polysaccharide produced by partial deacetylation of chitin, which is the main component of the exoskeletons of crustaceans and the cell walls of fungi. The protonation of the D-glucosamine units renders chitosan readily soluble and positively charged in acidic aqueous solution.[1] It is widely used in diverse biomedical applications, [2,3] gene therapy,[4] drug delivery,[5,6] and in removal of water pollutants.[7] Chitosan nanoparticles (NP) can be prepared by ionotropic gelation with tripolyphosphate anions.[8,9] They showed antibacterial activity[10] and were used as efficient carriers for proteins, peptides[11] and various types of drugs.[4] Commercially available chitosan provided NPs with wide size distribution, but the diminution of the molecular weight, degree of acetylation, acetic acid concentration, and the optimization of the temperature of the synthesis resulted in particles of low polydispersity.[12,13] To enhance the bioavailability of the drugs and the loading capacity of the carrier, hybrid NPs comprising cyclodextrin derivatives (CD) were developed.[14-18] The incorporation of CDbound triclosan and furosemide barely modified the size and zeta potential of chitosan NPs, but driving force of the inclusion of the drugs was significantly reduced.[19]

The main objective of the present study was to reveal the potential of 4sulfonatocalix[n]arenes (SCXn) to serve simultaneously as a crosslinking agent and a macrocyclic receptor in a self-assembled system with chitosan. Due to their multianionic character, SCXn cavitands are expected to establish electrostatic interactions with the protonated amino groups of chitosan, which may lead to connections between the polymer chains promoting NP formation. SCXn are biocompatible compounds exhibiting antiviral, antibacterial, antithrombic, and ion channel blocking activities.[20,21] Its $\pi$-electron rich, flexible cavity is capable of encapsulating a wide variety of organic molecules.[22,23] The 
complexation with compounds of biological and pharmaceutical importance received a particular attention.[21,24] We have previously studied the confinement of alkaloids of anticancer properties in SCXn and its effect on the fluorescent behavior. Berberine had a remarkably strong 1:1 binding to SCX8, but the driving force of the association considerably diminished with the macrocycle size, whereas the fluorescence quantum yield vanished with the increase of $\mathrm{pH} .[25]$ A structurally related alkaloid, coralyne, showed high affinity and multiple binding to SCXn. As many coralyne were able to associate with these hosts as the number of the 4-hydroxybenzene- sulfonate moieties in the macrocycle.[26] As an extension of these studies, now, we unravel whether the polymer chains of protonated chitosan can be crosslinked by SCXn to produce NPs, and how this process is influenced by alkaloids. The structures of the investigated compounds are presented in Scheme 1.

\section{Materials and methods}

\subsection{Materials}

4-Sulfonatocalix[4]arene (SCX4) (Fluka), 4-sulfonatocalix[6]arene (SCX6) and 4sulfonatocalix[8]arene (SCX8) (TCI) held 1:9, 1:13 and 1:21 stoichiometric amount of water in their crystal structure.[24] Coralyne chloride (Acros Organics) and berberine chloride (Sigma) were purified as described.[27,28] Water was freshly distilled twice from dilute $\mathrm{KMnO}_{4}$ solution. Three types of chitosan were used. Low molecular weight $(\mathrm{Mw})$ compound (ChA) was purchased from Fluka, whereas high purity chitosans from white mushroom $\mathrm{M}_{\mathrm{w}}=$ $60-120 \mathrm{kDa}(\mathrm{ChB})$, and $\mathrm{M}_{\mathrm{w}}=140-200 \mathrm{kDa}(\mathrm{ChC})$ were delivered by Aldrich. Their degree of deacetylation (\%) was determined using the ${ }^{1} \mathrm{H}$ NMR method developed by Hirai and coworkers.[29] The polymer amount is always given as the concentration of the saccharide unit. Measurements were performed at $298 \mathrm{~K}$. 


\subsection{Sample preparation}

Chitosan and SCXn were solved in $0.01 \mathrm{M} \mathrm{HCl}$ solution. After the adjustment of the $\mathrm{pH}$ by $\mathrm{NaOH}$ solution to the desired value, the necessary amounts of the two stock solutions were mixed under magnetic stirring at $200 \mathrm{rpm}$. The counterions of SCXn were $\mathrm{H}_{3} \mathrm{O}^{+}$and/or $\mathrm{Na}^{+}$depending on $\mathrm{pH}$. Alkaloid chloride loaded NPs were prepared using the solution of alkaloid-SCX8 complex instead of SCX8.

\subsection{Instrumentation}

The absorption spectra were recorded on an Agilent Technologies Cary 60 spectrophotometer. The turbidity $(\mathrm{T})$ of the samples were calculated from the absorbances (A) at $400 \mathrm{~nm}$ by the relationship $\mathrm{T}=1-10^{-\mathrm{A}}$. The $\mathrm{pH}$ of the solutions was measured with a Consort C832 equipment. To separate nanoparticles from the liquid phase, the solutions were ultracentrifuged in a Beckman Coulter apparatus (Optima Max-XP, type TLA 110 rotor) for 2 hours at $100000 \mathrm{rpm}$. The size and zeta potential of particles were determined on a Zetasizer Nano-ZS (Malvern Instrument) equipped with a $\mathrm{He}-\mathrm{Ne}$ laser $(\lambda=633 \mathrm{~nm}$, scattering angle $173^{\circ}$ ). Each result was the average of 12 runs of $10 \mathrm{~s}$ at $298 \mathrm{~K}$. Data were analyzed with the software developed by the manufacturer, and the mean particle diameters were calculated on the basis of intensity distribution. ${ }^{1} \mathrm{H}$ NMR spectra were recorded on a Bruker Avance 300 NMR spectrometer. Transmission electron microscopy (TEM) were done with a FEI Tecnai F20 microscope operating at an acceleration voltage of $200 \mathrm{kV}$. The samples were prepared as follows. A drop of the suspension was deposited on a Formvar (poly(vinylformal))/carbon-supported 400 grid mesh previously treated by air plasma for 40 s. After $1 \mathrm{~min}$, excess of liquid was removed with an absorbent paper and the grid was dried in air at room temperature. 


\section{Results and Discussion}

\subsection{Turbidity measurements in $0.01 \mathrm{M} \mathrm{HCl}$ solution}

Despite the lack of absorption of the components above $300 \mathrm{~nm}$, the apparent absorbance increased in this spectral range when chitosan was added to $0.017 \mathrm{mM}$ SCX8 solution in $0.01 \mathrm{M} \mathrm{HCl}$. Fig. 1 displays the SCX8-induced turbidity at $400 \mathrm{~nm}$ at various $r=[\mathrm{SCX} 8] /[$ chitosan] molar ratios for $\mathrm{ChA}$ and $\mathrm{ChC}$. The different molecular weight and degree of acetylation of the two types of chitosans (vide infra in Table 1) caused insignificant change in the experimental data. Three well-defined ranges appear, as shown by dashed lines in Fig. 1. At $0.004 \leq r \leq 0.08$, where chitosan was present in substantial excess, the turbidity barely varied. Coalescence was observed in the $0.08<r<0.27$ domain, whereas the turbidity gradually vanished at larger $r$ values. In $0.01 \mathrm{M} \mathrm{HCl}$ solution, SCX8 macrocycles had 8 negative charges because the sulfonato moieties were deprotonated, but the phenolic $\mathrm{OH}$ substituents did not dissociate.[30] Since only the free $\mathrm{NH}_{2}$ substituents of chitosan were protonated, the mean charge of the polymer repeating units corresponded to the degree of deacetylation. The charge neutralization, which took place at $r=0.105$ or 0.086 using ChA or ChC, respectively, brought about coalescence.

\subsection{Particle size at various SCX8: chitosan mixing ratios in $0.01 \mathrm{M} \mathrm{HCl}$}

To determine the size of particles in turbid solutions dynamic light scattering (DLS) experiments were performed. Protonated chitosan did not associate under our experimental conditions because of the electrostatic repulsion among the macromolecules. The scattered light intensity of protonated chitosan was low and increased by more than two orders of magnitude after SCX8 addition. Due to its polyanionic character, SCX8 could connect chitosan chains by Coulomb interaction with the $\mathrm{NH}_{3}{ }^{+}$substituents (Scheme 2). This led to 
nanoparticle (NP) formation in the $0.004 \leq r \leq 0.08$ mixing ratios. Fig. 2 displays a typical particle size distribution and the dependence of the mean NP diameter $(d)$ on the molar ratio of the components. At constant $0.59 \mathrm{mM}$ ChA concentration, $d=268 \pm 25 \mathrm{~nm}$ was found irrespective of the amount of SCX8 $(0.0047-0.040 \mathrm{mM})$. When $0.018 \mathrm{mM}$ SCX8 concentration was fixed, $d=190 \pm 20 \mathrm{~nm}$ was obtained in the $0.042 \leq r \leq 0.08$ range, whereas larger $d$ with broader size distribution appeared at lower $r$ values.

Our results demonstrate that the traditionally applied tripolyphosphate crosslinking anion can be replaced by SCX8, which does not lose its polyanionic character even in strongly acidic conditions. Tripolyphosphate cannot induce NP formation in strongly acidic solution because protonation eliminates most of its negative charges. The $\mathrm{pK}_{\mathrm{a}}$ values of its conjugated acids[31] are 1.0, 2.2, 2.3, 5.7 and 8.5. Since SCX8 is a stronger acid (pKa $<0.4)$, its sulfonate moieties are not protonated[30] even at $\mathrm{pH} 0.4$. Therefore, $\mathrm{SCX} 8$ is able to act as a crosslinking agent in a broad $\mathrm{pH}$ range.

\subsection{Alteration of molecular weight and deacetylation degree of chitosan}

To reveal whether the degree of polymerization and deacetylation influence the selfassembly with SCX8, experiments were performed in $0.01 \mathrm{M} \mathrm{HCl}$ with three types of chitosan, whose characteristics are given in Table 1. Insignificant difference was observed in the mean diameter of NPs when various chitosans were used in $0.59 \mathrm{mM}$ concentration and SCX8 amount was altered to reach $0.004 \leq r \leq 0.08$ range (Table 1). The width of the scattered light intensity distribution and the polydispersity index also varied less than the limit of experimental errors indicating that neither the polymer chain length nor the number of the ammonium substituents affected the association. Despite the insubstantial change in particle diameter, the scattered light intensity increased with gradual addition of SCX8 implying that $r$ change influenced only the number of NPs, but did not modify their size. The 
NPs were stable. The mean diameter of NPs and the intensity of scattered light altered insignificantly in one day at $0.59 \mathrm{mM}$ chitosan concentration in $0.01 \leq r \leq 0.06$ range irrespective of molecular weight and degree of deacetylation. As a representative example, Figure S1 in Supplementary Information displays that even the size distribution of NPs calculated on the basis of the scattered light intensity barely changed in one day.

Table 1 Characteristics of chitosan and NPs ${ }^{\mathrm{a}}$ in $0.01 \mathrm{M} \mathrm{HCl}$

\begin{tabular}{|c|c|c|c|c|}
\hline & $\begin{array}{c}\text { Molecular } \\
\text { weight } \\
\mathrm{kDa}\end{array}$ & $\begin{array}{c}\text { Degree of } \\
\text { deacetylation }\end{array}$ & $\begin{array}{c}\text { Mean diameter } \\
\mathrm{nm}\end{array}$ & PDI $^{\mathrm{b}}$ \\
\hline $\mathrm{ChA}$ & low $^{\mathrm{c}}$ & $84 \%$ & $268 \pm 25$ & 0.19 \\
\hline $\mathrm{ChB}$ & $60-120$ & $82 \%$ & $279 \pm 33$ & 0.19 \\
\hline $\mathrm{ChC}$ & $140-200$ & $69 \%$ & $262 \pm 31$ & 0.17 \\
\hline
\end{tabular}

a The parameters listed in the last two columns are the averages of the results obtained by addition of SCX8 to $0.59 \mathrm{mM}$ chitosan at $0.004 \leq r \leq 0.085$. ${ }^{b}$ polydispersity index; ${ }^{c}$ molecular weight range is not specified by the manufacturer.

\subsection{Effect of $p H$ and temperature on the particle size and zeta potential}

The charge of the polymer chain of chitosan arises from the protonation of its amino groups, which is influenced by the $\mathrm{pH}$. The negative logarithm of the proton dissociation constant $\left(\mathrm{pK}_{\mathrm{a}}\right)$ was reported to be between 6.17 and 6.51 depending on the molecular weight and degree of deacetylation.[32] The $\mathrm{pH}$ enhancement also affects the charge of SCX8 because the phenolic $\mathrm{OH}$ moieties[30] have a $\mathrm{pK}_{\mathrm{a}}$ of 3.44, 4.26, 7.78 and 10.3. At $\mathrm{pH} 4$, NPs could be prepared only at $0.004 \leq r \leq 0.065$ ratios in $0.59 \mathrm{mM}$ chitosan solutions. At higher $r$ values coalescence was observed. Coalescence took place already at $r \geq 0.02$ when the experiments were performed at $\mathrm{pH}$ 6. Due to the smaller degree of protonation of the polymer chain at higher $\mathrm{pH}$, incorporation of less SCX8 ensured charge neutrality, where the lack of 
electrostatic repulsion among particles led to coalescence. Zeta potential $(\zeta)$ measurements demonstrated the positive charge of NPs. The $\zeta$ of ChB-SCX8 NPs gradually diminished with the increase of $\mathrm{pH}$, but did not change with $r$ at a fixed $\mathrm{pH}$ in

Table 2 Variation of the parameters of chitosan-SCX8 NPs with $\mathrm{pH}$, molecular weight, and time at $0.59 \mathrm{mM}$ chitosan concentration

\begin{tabular}{|c|c|c|c|c|}
\hline $\mathrm{pH}$ & Chitosan & $\begin{array}{l}\text { Time after } \\
\text { mixing / h }\end{array}$ & $\begin{array}{c}\text { Mean diameter } \\
\mathrm{nm}\end{array}$ & $\mathrm{PDI}^{\mathrm{b}}$ \\
\hline \multirow{3}{*}{2} & \multirow{3}{*}{$\begin{array}{c}\text { ChA } \\
0.004 \leq r \leq 0.080\end{array}$} & 0 & $268 \pm 25$ & 0.19 \\
\hline & & 1 & $258 \pm 20$ & 0.16 \\
\hline & & 24 & $283 \pm 15$ & 0.17 \\
\hline \multirow{3}{*}{2} & \multirow{3}{*}{$\begin{array}{c}\mathrm{ChB} \\
0.004 \leq r \leq 0.080\end{array}$} & 0 & $279 \pm 35$ & $0.19 \pm 0.04$ \\
\hline & & 1 & $298 \pm 30$ & $0.19 \pm 0.04$ \\
\hline & & 24 & $320 \pm 45$ & $0.21 \pm 0.07$ \\
\hline \multirow{3}{*}{4} & \multirow{3}{*}{$\begin{array}{c}\mathrm{ChB} \\
0.015 \leq r \leq 0.065\end{array}$} & 0 & $149 \pm 18$ & $0.19 \pm 0.04$ \\
\hline & & 1 & $155 \pm 16$ & $0.18 \pm 0.04$ \\
\hline & & 24 & $177 \pm 17$ & $0.15 \pm 0.03$ \\
\hline \multirow{3}{*}{4} & \multirow{3}{*}{$\begin{array}{c}\mathrm{ChC} \\
0.015 \leq r \leq 0.065\end{array}$} & 0 & $181 \pm 13$ & $0.18 \pm 0.04$ \\
\hline & & 1 & $193 \pm 10$ & $0.15 \pm 0.03$ \\
\hline & & 24 & $226 \pm 10$ & $0.13 \pm 0.03$ \\
\hline \multirow{3}{*}{6} & \multirow{3}{*}{$\begin{array}{c}\mathrm{ChB} \\
0.008 \leq r \leq 0.024\end{array}$} & 0 & $149 \pm 7$ & $0.28 \pm 0.08$ \\
\hline & & 1 & $159 \pm 6$ & $0.23 \pm 0.03$ \\
\hline & & 24 & $153 \pm 7$ & $0.24 \pm 0.05$ \\
\hline
\end{tabular}

${ }^{\text {a }}$ Diameter is the average of the values measured in the $r$ range (given in the second column) where no coalescence occurs. ${ }^{b}$ polydispersity index

the range where stable NPs were produced. The mean zeta potentials of ChB-SCX8 NPs were 32.5, 29.1, and $21.2 \mathrm{mV}$ at $\mathrm{pH} \mathrm{2,4}$, and 6, respectively. The zeta potentials were almost insensitive to the variation of the molecular weight and the degree of deacetylation of chitosan. At $0.59 \mathrm{mM}$ chitosan concentration, the diameter and size distribution of NPs did not show any systematic change with SCX8 amount in the $r$ range given in Table 2 . Therefore, the parameters in Table 2 represent the average of the values measured at $r$ mixing 
ratios where stable NPs is produced. Considerably smaller NPs were prepared from ChB when $\mathrm{pH}$ was raised from 2 to 4 , but further $\mathrm{pH}$ increase to 6 did not lead to any further size decrease. At $\mathrm{pH} 4$, the interaction of SCX8 with $\mathrm{ChC}$ of high molecular weight promoted the assembly to somewhat larger NPs compared to $\mathrm{ChB}$, which slightly grew in one day. Contrarily, NPs composed of ChB altered less than the limit of experimental errors during this time indicating the larger stability of NPs comprising shorter chitosan chains. At a given concentration (below $3 \mathrm{mM}$ ), the NP size was always insensitive to $r$ within the $0.015 \leq r \leq$ 0.065 range at $\mathrm{pH}$ 4. However, the NP diameter and polydispersity index (PDI) grew with ChB concentration (Fig. 3). About twice larger particles formed when $\mathrm{ChB}$ amount was raised from 0.59 to $3 \mathrm{mM}$, whereas PDI only slightly increased.

Figure S2 in Supplementary Information presents the diameter and PDI of NPs produced at $r=0.054$ mixing ratios in $0.01 \mathrm{M} \mathrm{HCl}$ as a function of preparation temperature. Only minor effect is observed. Slightly larger NPs were formed with somewhat broader size distribution when the temperature was raised from 298 to $323 \mathrm{~K}$.

\subsection{Determination of SCX8 content and morphology of NPS}

To reveal the extent of SCX8 binding in NPs, the dispersion was ultracentrifuged for 2 hours, and the SCX8 content of the supernatant was determined by spectrophotometric method. The characteristic absorption band of SCX8 always vanished indicating that negligible amount of SCX8 remained in the solvent under all experimental conditions after NP formation. The electrostatic attraction between the oppositely charged SCX8 and protonated chitosan led to crosslinking among the polymer chains inducing thereby NP formation. The multiple charge of the cavitand facilitated the interaction with several macromolecules, and screened the electrostatic repulsion among the ammonium substituents. In stable NPs, less than stoichiometric amount of SCX8 is embedded. 
The morphology of the NPs was characterized by TEM and as a representative example, we studied the NPs at $\mathrm{r}=0.057$ and $\mathrm{pH} 2$ and 4 (Fig. 4). The observed nano-objects are relatively polydisperse, in agreement with the PDI around 0.2. Their size is around 150$200 \mathrm{~nm}$, as determined by DLS. The NPs exhibit a loose structure, which may facilitate the release of the included alkaloid.

\subsection{Effect of macrocycle size alteration on NP size}

Not only SCX8 but also its smaller homologues SCX6 and SCX4 could induce ChA association to NPs. The charge of these macrocycles corresponds to the number of their 4-sulfonatophenol units[30] at $\mathrm{pH}$ 2. Coalescence was always observed around charge neutralization. As seen in Fig. 5, SCX4 promoted the assembly to smaller NPs $(d=150 \pm 20$ $\mathrm{nm}$ ), but the NP diameter did not differ for SCX6 and SCX8. The particle size was also independent of the relative amount of the components. The SCX4 has smaller conformational mobility than the other homologues due to the stabilization of the truncated cone shaped macrocycle by hydrogen bonding among the phenolic $\mathrm{OH}$-groups and steric hindrance of the conformation change. The smaller size and the relatively rigid molecular structure lead to smaller NPs compared to those developed with SCX6 and SCX8.

\subsection{Alkaloid confinement in NP}

We have previously demonstrated that SCXn cavitands are capable of encapsulating alkaloids of pharmaceutical importance.[25,26] Berberine $\left(\mathrm{B}^{+}\right)$was found to bind very strongly to SCX8 with equilibrium constant ${ }^{23}$ of $2.4 \times 10^{5} \mathrm{M}^{-1}$ at $\mathrm{pH} 2$. In contrast, the lack of change in the $\mathrm{B}^{+}$absorption and fluorescence spectra indicated that $\mathrm{B}^{+}$did not produce complex with $1.2 \mathrm{mM}$ ChA because the electrostatic repulsion between the two positively charged compounds prevented the binding. The question arose whether SCX8 in NPs could 
include this natural isoquinoline alkaloid. $\mathrm{ChA}$ in $0.01 \mathrm{M} \mathrm{HCl}$ was mixed with solutions of $\mathrm{B}^{+}-\mathrm{SCX} 8$ complex. The size and stability of NPs produced thereby matched those comprising no $\mathrm{B}^{+}$. Table 3 reports the mean diameter and polydispersity index of NPs. NP diameters increase with ChA concentration, but remain almost constant when $\mathrm{B}^{+}$and SCX8 concentrations are varied keeping chitosan concentration unchanged. Negligible particle diameter alteration was observed in three days even in the presence of alkaloid and the lack of change in the absorption spectra indicated that no $\mathrm{B}^{+}$decomposition occurred. To determine the fraction of $\mathrm{B}^{+}$embedded in $\mathrm{NP}$, the dispersed phase was separated by ultracentrifugation and $\mathrm{B}^{+}$concentration in the supernatant $\left(\left[\mathrm{B}^{+}\right]_{\mathrm{S}}\right)$ was measured by spectrophotometric method. The association efficiency (AE) and loading capacity (LC) was calculated as follows:

$$
\begin{gathered}
A E=\frac{A-A_{S}}{A} \times 100 \\
L C=\frac{A-A_{S}}{C h+S C X 8} \times 100
\end{gathered}
$$

where A, Ch, and SCX8 denotes the total amounts of alkaloid chloride, chitosan, and SCX8, respectively. $A_{S}$ stands for the amount of alkaloid chloride in the supernatant. The absorption spectrum suggests that the supernatant did not contain $\mathrm{B}^{+}-\mathrm{SCX} 8$ complex or SCX8 indicating that SCX8 is fully incorporated in NPs. However, $\mathrm{B}^{+}$appears in the supernatant because competitive binding of the ammonium moieties of protonated chitosan to SCX8 partly expels $\mathrm{B}^{+}$from the macrocycle cavity. Therefore, AE varies between 17 and $37 \%$, but LC remains below $1 \%$.

In contrast to the moderate binding capability of $\mathrm{B}^{+}$, its synthetic analogue, coralyne $\left(\mathrm{Cor}^{+}\right)$was readily embedded in chitosan-SCX8 NPs. This is in accordance with previous findings that unlike 1:1 complex formation with berberine, SCX8 can associate with $8 \mathrm{Cor}^{+}$ molecules.[26] Table 4 summarizes the association efficiencies and loading capacities 
Table 3 Effect of total concentration of the component on the association efficiency and loading capacity of berberine in $0.01 \mathrm{M} \mathrm{HCl}(\mathrm{pH} 2)$

\begin{tabular}{|c|c|c|c|c|c|c|c|c|}
\hline \multicolumn{3}{|c|}{ Total concentration } & \multirow{2}{*}[\mathrm{SCX}8]{$/[\mathrm{ChA}]$} & \multirow{2}{*}[\mathrm{B}^{+}]{$/[\mathrm{SCX} 8]$} & \multirow{2}{*}{$\mathrm{AE} \%$} & \multirow{2}{*}{$\mathrm{LC} w \%$} & \multirow{2}{*}{$\begin{array}{c}\text { Mean } \\
\text { diameter } \\
n m\end{array}$} & \multirow{2}{*}{ PDI } \\
\hline$[\mathrm{ChA}] / \mathrm{mM}$ & {$[\mathrm{SCX} 8] / \mathrm{mM}$} & {$\left[\mathrm{B}^{+}\right] / \mathrm{mM}$} & & & & & & \\
\hline 2.37 & 0.10 & 0.020 & 0.043 & 0.2 & 37 & 0.52 & 550 & 0.42 \\
\hline 1.77 & 0.10 & 0.020 & 0.057 & 0.2 & 31 & 0.54 & 590 & 0.32 \\
\hline 1.18 & 0.10 & 0.020 & 0.084 & 0.2 & 30 & 0.65 & 650 & 0.30 \\
\hline 0.59 & 0.050 & 0.020 & 0.084 & 0.4 & 22 & 0.95 & 270 & 0.19 \\
\hline 0.59 & 0.030 & 0.020 & 0.05 & 0.66 & 17 & 0.88 & 260 & 0.19 \\
\hline 0.59 & 0.050 & 0.010 & 0.084 & 0.2 & 22 & 0.48 & 300 & 0.22 \\
\hline
\end{tabular}


Table 4 Efficiency of $\mathrm{Cor}^{+}$association to ChB-SCX8 NPs under various experimental conditions at $0.59 \mathrm{mM}$ ChB concentration

\begin{tabular}{|c|c|c|c|c|c|c|c|c|}
\hline \multirow{2}{*}{$\mathrm{pH}$} & \multicolumn{2}{|c|}{ Total concentration } & \multirow{2}{*}[\mathrm{SCX}8]{$/[\mathrm{ChB}]$} & \multirow{2}{*}[\mathrm{Cor}^{+}]{$/[\mathrm{SCX} 8]$} & \multirow{2}{*}{$\mathrm{AE} \%$} & \multirow{2}{*}{$\mathrm{LC} \%$} & \multirow{2}{*}{$\begin{array}{c}\text { Mean } \\
\text { diameter } \\
\text { nm }\end{array}$} & \multirow{2}{*}{ PDI } \\
\hline & {$[\mathrm{SCX} 8] / \mathrm{mM}$} & {$\left[\mathrm{Cor}^{+}\right] / \mathrm{mM}$} & & & & & & \\
\hline \multirow{4}{*}{2} & 0.014 & 0.008 & 0.024 & 0.56 & 97 & 2.6 & 230 & 0.26 \\
\hline & 0.014 & 0.016 & 0.024 & 1.1 & 98 & 5.2 & 170 & 0.34 \\
\hline & 0.014 & 0.022 & 0.024 & 1.6 & 98 & 7.1 & 150 & 0.37 \\
\hline & 0.047 & 0.022 & 0.08 & 0.48 & 99 & 5.1 & 300 & 0.31 \\
\hline \multirow{10}{*}{4} & 0.015 & 0.008 & 0.025 & 0.53 & 80 & 2.1 & 140 & 0.22 \\
\hline & 0.015 & 0.016 & 0.025 & 1.1 & 81 & 4.2 & 160 & 0.24 \\
\hline & 0.015 & 0.022 & 0.025 & 1.5 & 82 & 5.9 & 170 & 0.27 \\
\hline & 0.015 & 0.045 & 0.025 & 3 & 81 & 12 & 200 & 0.37 \\
\hline & 0.015 & 0.067 & 0.025 & 4.5 & 86 & 19 & 180 & 0.51 \\
\hline & 0.039 & 0.003 & 0.066 & 0.083 & 94 & 0.7 & 190 & 0.17 \\
\hline & 0.039 & 0.016 & 0.066 & 0.4 & 91 & 3.7 & 230 & 0.18 \\
\hline & 0.039 & 0.022 & 0.066 & 0.56 & 93 & 5.2 & 220 & 0.22 \\
\hline & 0.039 & 0.045 & 0.066 & 1.1 & 91 & 10 & 230 & 0.25 \\
\hline & 0.039 & 0.067 & 0.066 & 1.7 & 93 & 16 & 240 & 0.17 \\
\hline
\end{tabular}


calculated on the basis of equations 1 and 2. AE reaches 99\%. At $\mathrm{pH} 2$, practically complete binding occurred under our experimental conditions irrespectively of $\mathrm{Cor}^{+}$concentration and NP composition. Confinement of even more than $1 \mathrm{Cor}^{+}$per SCX8 molecules was reached. The mean diameter and polydispersity index of NPs are also included in Table 4. At pH 2, the NP size barely changed at constant $[\mathrm{SCX} 8] /[\mathrm{ChB}]$. However, NP diameter grew from ca. 180 $\mathrm{nm}$ to $300 \mathrm{~nm}$ when $[\mathrm{SCX} 8] /[\mathrm{ChB}]$ was varied from 0.024 to 0.080 . Moreover, Cor ${ }^{+}$ incorporation increased the polydispersity, and diminished the temporal stability of NPs. In less acidic solution ( $\mathrm{pH} 4)$, stable, smaller and more monodisperse $\mathrm{Cor}^{+}-\mathrm{NP}$ aggregates were found, although the association efficiency became slightly lower than at $\mathrm{pH} 2$ (Table 4). Nevertheless, the fraction of bound $\operatorname{Cor}^{+}$was always above 80 and $90 \%$ at $[\mathrm{SCX} 8] /[\mathrm{ChB}]=$ 0.025 and 0.067 , respectively. The NP diameter slightly grew upon addition of $22 \mu \mathrm{M}$ Cor $^{+}$ from 140 to $170 \mathrm{~nm}$ at $[\mathrm{SCX} 8] /[\mathrm{ChB}]=0.025$ and from 190 to $220 \mathrm{~nm}$ at $[\mathrm{SCX} 8] /[\mathrm{ChB}]=$ 0.066. At the latter [SCX8]/[ChB] ratio, NPs had larger stability, narrower size distribution, and $\mathrm{Cor}^{+}$concentration could be raised to $70 \mu \mathrm{M}$ without any stability loss and $15 \%$ loading capacity was reached. Above $\left[\mathrm{Cor}^{+}\right] /[\mathrm{SCX} 8]$ molar ratio of 1.7 , reduced temporal stability and larger polydispersity of NPs were observed. Confinement in NP did not alter the stability of $\mathrm{Cor}^{+}$. The temporal stability of the absorption spectra indicated that neither of the applied experimental conditions induced decomposition.

\section{Conclusions}

SCX8-induced supramolecular crosslinking of protonated chitosan is a straightforward, mild method for the preparation of NPs capable of carrying pharmaceutically important alkaloids. In these self-assembled systems, SCX8 not only promotes the association to NPs, but also provides binding sites for inclusion complex formation with alkaloid molecules. The substantial binding affinity to SCX8 ensured $\mathrm{B}^{+}$or $\mathrm{Cor}^{+}$confinement in NPs despite the 
positive charge of NPs. SCXn macrocycles could replace the often employed tripolyphosphate crosslinking agent with the additional benefit of forming host-guest inclusion complexes. The NP size can be fine-tuned by the variation of $\mathrm{pH}, \mathrm{SCXn}$ size and chitosan concentration, whereas other experimental conditions slightly affect NP formation. A significant advantage of SCXn utilization for the initiation of self-organization into NPs is that these biocompatible compounds keep polyanionic character and as a consequence, the crosslinking ability even in strongly acidic conditions where conventional polyanions such as for example tripolyphosphate cannot be applied.

\section{Acknowledgement}

We appreciate the support of this work by the Hungarian Scientific Research Fund (OTKA, Grant K104201) and the bilateral program between CNRS and the Hungarian Academy of Sciences. Z. M. thanks the support of the János Bolyai Research Scholarship of the Hungarian Academy of Sciences.

\section{Appendix A. Supplementary data}

Supplementary data associated with this article can be found, in the online version, at $\underline{\text { http://dx.doi.org/ }}$

Conflict of Interest: The authors declare that they have no conflict of interest.

\section{References}

1. Rinaudo M, Pavlov G, Desbrières J (1999) Influence of acetic acid concentration on the solubilization of chitosan. Polymer 40 (25):7029-7032. doi:http://dx.doi.org/10.1016/S0032$\underline{3861(99) 00056-7}$ 
2. Dash M, Chiellini F, Ottenbrite RM, Chiellini E (2011) Chitosan-A versatile semisynthetic polymer in biomedical applications. Prog Polym Sci 36 (8):981-1014. doi:http://dx.doi.org/10.1016/j.progpolymsci.2011.02.001

3. Kumar GS, Hazra S (2014) Sanguinarine, a promising anticancer therapeutic: photochemical and nucleic acid binding properties. RSC Adv 4 (99):56518-56531. doi:10.1039/c4ra06456a

4. Garcia-Fuentes M, Alonso MJ (2012) Chitosan-based drug nanocarriers: Where do we $\begin{array}{lllll}\text { stand? } & \text { J } & \text { Controlled } & \text { Release } & 161\end{array}$ doi:http://dx.doi.org/10.1016/j.jconrel.2012.03.017

5. van der Lubben IM, Verhoef JC, Borchard G, Junginger HE (2001) Chitosan and its derivatives in mucosal drug and vaccine delivery. Eur J Pharm Sci 14 (3):201-207. doi:http://dx.doi.org/10.1016/S0928-0987(01)00172-5

6. Nagpal K, Singh SK, Mishra DN (2010) Chitosan Nanoparticles: A Promising System in Novel Drug Delivery. Chem Pharm Bull 58 (11):1423-1430. doi:10.1248/cpb.58.1423

7. Vakili M, Rafatullah M, Salamatinia B, Abdullah AZ, Ibrahim MH, Tan KB, Gholami Z, Amouzgar P (2014) Application of chitosan and its derivatives as adsorbents for dye removal from water and wastewater: A review. Carbohydr Polym 113 (0):115-130. doi:http://dx.doi.org/10.1016/j.carbpol.2014.07.007

8. Calvo P, Remuñán-López C, Vila-Jato JL, Alonso MJ (1997) Novel hydrophilic chitosanpolyethylene oxide nanoparticles as protein carriers. J Appl Polym Sci 63 (1):125-132. doi:10.1002/(SICI)1097-4628(19970103)63

9. Huang K-S, Sheu Y-R, Chao I-C (2009) Preparation and Properties of Nanochitosan. Polymer-Plastics Technology and Engineering $48 \quad$ (12):1239-1243. doi:10.1080/03602550903159069 
10. Qi L, Xu Z, Jiang X, Hu C, Zou X (2004) Preparation and antibacterial activity of $\begin{array}{lllll}\text { chitosan } & \text { nanoparticles. } & \text { Carbohydr } & \text { Res } & 339\end{array}$ (16):2693-2700. doi:http://dx.doi.org/10.1016/j.carres.2004.09.007

11. Janes KA, Alonso MJ (2003) Depolymerized chitosan nanoparticles for protein delivery: Preparation and characterization. J Appl Polym Sci 88 (12):2769-2776. doi:10.1002/app.12016

12. Zhang H, Oh M, Allen C, Kumacheva E (2004) Monodisperse Chitosan Nanoparticles for Mucosal Drug Delivery. Biomacromolecules 5 (6):2461-2468. doi:10.1021/bm0496211

13. Fan W, Yan W, Xu Z, Ni H (2012) Formation mechanism of monodisperse, low molecular weight chitosan nanoparticles by ionic gelation technique. Colloids and Surfaces B: Biointerfaces 90 (0):21-27. doi:http://dx.doi.org/10.1016/j.colsurfb.2011.09.042

14. El-Feky GS, El-Banna ST, Khalil SKH (2013) Preparation, in vitro and in vivo evaluation of oral indomethacin-HP-B-cyclodextrin loaded chitosan nanoparticles. International Journal of Pharmacy and Pharmaceutical Sciences 5 (4):638-645

15. Khalil SKH, El-Feky GS, El-Banna ST, Khalil WA (2012) Preparation and evaluation of warfarin- $\beta$-cyclodextrin loaded chitosan nanoparticles for transdermal delivery. Carbohydr Polym 90 (3):1244-1253. doi:10.1016/j.carbpol.2012.06.056

16. Trapani A, Lopedota A, Franco M, Cioffi N, Ieva E, Garcia-Fuentes M, Alonso MJ (2010) A comparative study of chitosan and chitosan/cyclodextrin nanoparticles as potential carriers for the oral delivery of small peptides. Eur J Pharm Biopharm 75 (1):26-32. doi:10.1016/j.ejpb.2010.01.010

17. Teijeiro-Osorio D, Remunán-López C, Alonso MJ (2009) Chitosan/cyclodextrin nanoparticles can efficiently transfect the airway epithelium in vitro. Eur J Pharm Biopharm 71 (2):257-263. doi:http://dx.doi.org/10.1016/j.ejpb.2008.09.020 
18. Krauland AH, Alonso MJ (2007) Chitosan/cyclodextrin nanoparticles as macromolecular drug delivery system. Int J Pharm 340 (1-2):134-142. doi:10.1016/j.ejpb.2005.12.006

19. Maestrelli F, Garcia-Fuentes M, Mura P, Alonso MJ (2006) A new drug nanocarrier consisting of chitosan and hydoxypropylcyclodextrin. Eur J Pharm Biopharm 63 (2):79-86. doi:10.1016/j.ejpb.2005.12.006

20. Perret F, Lazar AN, Coleman AW (2006) Biochemistry of the para-sulfonatocalix[n]arenes. Chem Commun (23):2425-2438. doi:10.1039/b600720c

21. Perret F, Coleman AW (2011) Biochemistry of anionic calix[n]arenes. Chem Commun 47 (26):7303-7319. doi:10.1039/c1cc11541c

22. Dsouza RN, Pischel U, Nau WM (2011) Fluorescent dyes and their supramolecular host/guest complexes with macrocycles in aqueous solution. Chem Rev 111 (12):7941-7980. doi:10.1021/cr200213s

23. Guo D-S, Wang K, Liu Y (2008) Selective binding behaviors of p-sulfonatocalixarenes in aqueous solution. J Incl Phenom Macrocycl Chem 62 (1):1-21. doi:10.1007/s10847-008$9452-2$

24. Yang W, Villiers MMd (2004) The solubilization of the poorly water soluble drug nifedipine by water soluble 4-sulphonic calix[n]arenes. Eur J Pharm Biopharm 58:629-636. doi:10.1016/j.ejpb.2004.04.010

25. Megyesi M, Biczók L (2006) Considerable fluorescence enhancement upon supramolecular complex formation between berberine and p-sulfonated calixarenes. Chem Phys Lett 424 (1-3):71-76. doi:10.1016/j.cplett.2006.04.016

26. Megyesi M, Biczók L (2010) Considerable change of fluorescence properties upon multiple binding of coralyne to 4-sulfonatocalixarenes. J Phys Chem B 114 (8):2814-2819. doi:10.1021/jp910418k 
27. Megyesi M, Biczók L, Görner H (2009) Dimer-promoted fluorescence quenching of coralyne by binding to anionic polysaccharides. Photochem Photobiol Sci 8 (4):556-561. doi:10.1039/b822649k

28. Miskolczy Z, Biczók L (2014) Kinetics and Thermodynamics of Berberine Inclusion in Cucurbit[7]uril. J Phys Chem B 118 (9):2499-2505. doi:10.1021/jp500603g

29. Hirai A, Odani H, Nakajima A (1991) Determination of degree of deacetylation of chitosan by 1H NMR spectroscopy. Polym Bull 26 (1):87-94. doi:10.1007/BF00299352

30. Suga K, Ohzono T, Negishi M, Deuchi K, Morita Y (1998) Effect of various cations on the acidity of p-sulfonatocalixarenes. Supramol Sci 5 (1-2):9-14. doi:10.1016/S09685677(97)00074-6

31. Koper GJM, Minkenberg CB, Upton IS, van Esch JH, Sudhölter EJR (2009) Quantitatively Interpreting Thermal Behavior of Self-Associating Systems. J Phys Chem B 113 (47):15597-15601. doi:10.1021/jp909153n

32. Wang QZ, Chen XG, Liu N, Wang SX, Liu CS, Meng XH, Liu CG (2006) Protonation constants of chitosan with different molecular weight and degree of deacetylation. Carbohydr Polym 65 (2):194-201. doi:http://dx.doi.org/10.1016/j.carbpol.2006.01.001 


\section{Captions}

Scheme 1 Chemical structure of the studied compounds

Scheme 2 Illustration of the association between protonated chitosan molecules and SCX8

Fig. 1 Alteration of the turbidity at $400 \mathrm{~nm}$ as a function of the [SCX8]/[chitosan] molar ratio in $0.01 \mathrm{M} \mathrm{HCl}$. SCX8 concentration was kept constant $(0.017 \mathrm{mM})$ and $\mathrm{ChA}(\boldsymbol{\Delta})$ or $\mathrm{ChC}(\mathrm{O})$ amount were varied. Measurements were carried out 2 min after mixing of the components. Dashed lines indicates the range of coalescence $(0.08<r<0.27)$.

Fig. 2 (A) Typical size distributions of NPs after mixing $0.036 \mathrm{mM} \mathrm{SCX8}$ and $0.59 \mathrm{mM}$ ChA in $0.01 \mathrm{M} \mathrm{HCl}$. (B) Variation of the mean diameter of NPs as a function of the molar ratio of the components at $[\mathrm{ChA}]=0.59 \mathrm{mM}$.

Fig. 3 (A) Alteration of the particle diameter $(d)$ and (B) polydispersity index (PDI) with ChB concentration at $\mathrm{pH} 4$ solution immediately after mixing ( $\mathbf{\square})$, in an hour $(\mathrm{O})$, and in a day $(\boldsymbol{\Delta})$. Each point represents the average $d$ and PDI values in the $0.015 \leq r \leq 0.065$ domain at constant $\mathrm{ChB}$ concentration.

Fig. 4 TEM images of SCX8-ChB NPs formed at $r=0.057$ and (A) $\mathrm{pH} 2$ and (B) $\mathrm{pH} 4$. $[\mathrm{ChB}]=0.59 \mathrm{mM}$

Fig. 5 Particle diameter as a function of the mixing ratio of the components in the case of $\operatorname{SCX} 4(\boldsymbol{\nabla}), \operatorname{SCX} 6(\boldsymbol{\nabla})$, and $\operatorname{SCX} 8(O)$ in $0.01 \mathrm{M} \mathrm{HCl}$. [ChA] $=0.30 \mathrm{mM}$ 